\title{
Presentación Anuario de Derechos Humanos 2011
}

Tenemos el agrado de presentar hoy el séptimo número del Anuario de Derechos Humanos del Centro de Derechos Humanos de la Facultad de Derecho de la Universidad de Chile, publicación consagrada desde su comienzo al análisis de los más relevantes desarrollos doctrinarios, legales y jurisprudenciales en el campo de los derechos humanos y áreas afines que han tenido lugar en el año precedente en el plano nacional e internacional.

Como es habitual, el Anuario contiene dos artículos principales sobre un tema que su Comité Editorial considera de interés destacar. Este Anuario dedica esta sección al tema del tratamiento de las violaciones de derechos humanos en países en transición a la democracia, quizás uno de los temas más importantes que se han desarrollado a fines del siglo XX y comienzos del siglo XXI. Uno de estos trabajos pertenece a Pablo de Greiff, ex Profesor Asociado del Departamento de Filosofía en la Universidad de Nueva York en Buffalo y del Laurance S. Rockefeller Fellow del Centro de Valores Humanos en la Universidad de Princeton; actualmente, Director de Investigaciones del International Center for Transitional Justice en Nueva York; en su trabajo, él autorreflexiona sobre el desarrollo de la Justicia Transicional, los retos pendientes para un más acabado manejo de este complejo tema, esbozando finalmente una concepción normativa de la justicia transicional. La autora del otro artículo es Kathryn Sikkink, Profesora Regents y de McKnight Presidential Chair en Ciencias Políticas de la Universidad de Minnesota, autora de varias publicaciones en el tema, quien analiza en su investigación el efecto disuasivo de los juicios por violaciones de derechos humanos y cómo ellos contribuyen a un mejoramiento de la situación de los derechos humanos en los países en que se llevan a cabo.

El simposio de este número enfrenta el problema de las parejas de un mismo sexo, cuestión candente en un número significativo de países de la región, que incluso ha empezado a ocupar la agenda de los órganos legislativos de algunos de ellos. Los invitados a participar en este ejercicio de confrontación de ideas son Hernán Corral, Licenciado en Derecho de la Pontificia Universidad Católica de Chile, doctor en Derecho de la Universidad de Navarra, España, y Profesor de Derecho Civil de la Universidad de los Andes; Rolando Jiménez, presidente del Movimiento de Integración y Liberación Homosexual (MOVILH); Marcela Rodríguez, diputada argentina, abogada de la Universidad de Buenos Aires, Máster en Derecho de la Universidad de Yale (EE.UU.), miembro de la Cámara de Diputados de Argentina y Vicepresidenta III de la misma entre 2008 y 2009; Albie Sachs, ex Juez del Tribunal Constitucional de Sudáfrica y autor de numerosas e importantes publicaciones; y Macarena Sáez, Profesora de Derecho de American University, Washington College of Law en Estados Unidos, donde enseña Derecho de Familia y Derecho Comparado; desde 2008 coordina la Red de Académicos Latinoamericanos en Género, Sexualidad y Derecho, ALAS, académica de American University, Washington D.C.

Las secciones destinadas a lo internacional y a lo nacional dan cuenta de asuntos que tuvieron lugar en el curso de 2010 que se han seleccionado por su importancia. En el ámbito internacional 
se abordan varios temas. El primero es el de la ley SB 1070 de Arizona sobre inmigrantes, trabajo realizado por Denisse Gilman, profesora en la Facultad de Derecho de la Universidad de Texas, donde codirige la Clínica de Inmigración. El segundo se refiere a los derechos sexuales y reproductivos de las mujeres cuya autora es Patricia Laurenzo, Licenciada en Derecho de la Universidad de Mendoza, Argentina, y doctorada en la Universidad Complutense de Madrid; catedrática de Derecho Penal y Directora del Departamento de Derecho Público de la Universidad de Málaga, España; el artículo analiza la reciente Ley Orgánica 2/2010 de España sobre "Salud sexual y reproductiva y de la interrupción voluntaria del embarazo" que establece una nueva regulación del aborto no punible. El tercero es obra de Catharine MacKinnon, Elizabeth A. Long Professor of Law en la Universidad de Michigan y Consultora especial de Género para la Fiscalía de la Corte Penal Internacional, de reconocida reputación en el campo de los estudios feministas. En el artículo se dan las bases para un enfoque realista y constructivo para el tráfico sexual al analizar los aciertos y fallas, y los paralelos y convergencias entre el maltrato físico y la prostitución criticando una sentencia de la Corte Europea de Derechos Humanos sobre tráfico sexual, Rantsev v. Cyprus y Rusia, tema fundamental de hoy en la región. El último artículo, escrito por Cecilia Medina, ex jueza y presidenta de la Corte Interamericana de Derechos Humanos, describe y examina la última modificación de los Reglamentos de la Comisión y Corte Interamericanas de Derechos Humanos, que contienen enmiendas significativas en relación con el papel que le corresponde a la Comisión en los juicios ante la Corte. Como siempre, esta sección internacional examina la jurisprudencia de la Corte Interamericana de Derechos Humanos, reseña llevada a cabo por Claudio Nash y Claudia Sarmiento, ambos investigadores de este Centro.

La sección nacional analiza la orden de detención de la Corte Suprema chilena contra el presidente de Sudán Omar AI Bashir, con la cual Chile empieza a asumir su papel de Estado parte del Estatuto de la Corte Penal Internacional; el trabajo fue realizado por Claudia Cárdenas, Magíster y Doctora en Derecho por la Universidad Humboldt de Berlín, profesora del Departamento de Ciencias Penales de la Facultad de Derecho de la Universidad de Chile y hoy adscrita al programa de Doctorado de la misma Facultad. Luis Cordero, Doctor en Derecho (U. de Lleida) y Magíster en Políticas Públicas con mención en Economía (U. de Chile), profesor de Derecho Administrativo e investigador del Centro de Regulación y Competencia de la Facultad de Derecho, Universidad de Chile, comenta la sentencia de inconstitucionalidad emitida por el Tribunal Constitucional chileno sobre la tabla de factores para los cobros a los usuarios de ISAPRES (Instituciones de Salud Previsional) y los efectos que se provocaron en la operación del sistema de seguros de salud privado y también en sus usuarios. Hernán Quezada, Doctor en Derecho de las Universidades de Hamburgo y de Estrasburgo; actualmente abogado de la Dirección de Asuntos Jurídicos de la Cancillería y Profesor de Derecho Internacional en la Universidad Academia de Humanismo Cristiano, analiza la sentencia dictada por la Corte Suprema chilena que puso fin al proceso penal en el caso del asesinato de Carlos Prats, refiriéndose, entre otros temas, a la aplicación de la llamada "media prescripción" que permite una reducción importante de las penas. María Paz Gatica, Abogada, Licenciada en Ciencias Jurídicas y Sociales y profesora de Derecho Civil de esta Facultad, reflexiona sobre el destino de la sociedad conyugal. Finalmente José Zalaquett, codirector del Centro de Derechos Humanos entre los años 2002 y marzo de 2011 y actual profesor de Derecho Internacional de la Universidad de Chile, Doctor Honoris Causa por las universidades de Notre Dame y City University of New York, escribe intentando aclarar, en sus distintos aspectos, las normas y conceptos relativos a los conflictos de intereses para terminar revisando las principales iniciativas y leyes adoptadas en Chile sobre esta materia en las últimas dos décadas.

El tema en debate de este número es el de la libertad de conciencia, enfocado por dos académicos. Uno es Daniel Loewe, profesor titular de la Escuela de Gobierno de la Universidad Adolfo lbáñez 
en Santiago de Chile, Doctor en filosofía (summa cum laude) de la Universidad Eberhard Karl de Tübingen, Alemania, y miembro del Research Centre for Political Philosophy y del International Centre for Ethics in the Sciences and Humanities de la Universidad Tübingen. El enfoca el tema con una perspectiva liberal y defiende la neutralidad del Estado en materia de religión, lo que implica que las razones religiosas a favor o en contra de leyes, normativas o políticas públicas no son aceptables; una posición contraria viola el respeto debido al derecho de los individuos de tener o no tener una religión y la obligación del Estado de ser imparcial. El otro es Waldo Romo, Magíster en Teología de la Universidad Católica y con una especialización en Moral en el Instituto Superior de Ciencias Morales de Madrid; actualmente, profesor de Moral de la Persona (moral sexual y moral de la vida) en la Facultad de Teología y profesor de Teología del Matrimonio en la misma Facultad y en el Seminario Pontificio Mayor. Este artículo analiza la renovación teológica ocurrida a partir del Concilio Vaticano II y revisando ese proceso y fundamentando la legitimidad de la intervención de la Iglesia Católica en los debates valóricos.

Finalmente, este Anuario termina con dos entrevistas: una -realizada por Verónica Undurraga, investigadora de este Centro- a María Gracia Cariola, abogada de la Pontificia Universidad Católica de Chile, Master in Comparative Jurisprudence de la Universidad de Nueva York, quien fuera presidenta de la Comisión Asesora Presidencial Mujer, Trabajo y Maternidad convocada por el Presidente Sebastián Piñera, con amplia participación en empresas privadas. El tema de la entrevista es "Una mirada al proyecto de ley que crea el permiso postnatal parental". En la otra, Ilevada a cabo por Silvana Lauzán, también investigadora del Centro, se entrevistó a Leonardo Filippini, licenciado de la Universidad de Buenos Aires, Máster en Derecho de la Universidad de Palermo y de la Universidad de Yale; actualmente, profesor de grado y posgrado en la Facultad de Derecho de la Universidad de Palermo, Investigador del Centro Internacional para la Justicia Transicional (ICTJ) y candidato doctoral en la Escuela de Derecho de Yale. El título de la entrevista es "Sáquenme de Estocolmo si me enamoro de mi secuestrador".

A fin de difundir más ampliamente el Anuario, el Centro de Derechos Humanos lo publica en forma impresa y paralelamente en formato digital en la página www.cdh.uchile.cl/publicaciones/ anuarios. En esta versión digital existen links que permiten consultar los textos de los fallos o normas legales que se comentan.

El Centro de Derechos Humanos agradece la participación del profesor Zalaquett, codirector de este Centro hasta marzo de 2011, en la elaboración de este Anuario.

Junto con extender nuestros agradecimientos a los autores y autoras que han hecho posible esta edición del Anuario de Derechos Humanos con sus artículos y opiniones, nos hacemos el deber de reconocer con gratitud el aporte de las instituciones donantes que hacen posible el financiamiento de los distintos programas y actividades del Centro de Derechos Humanos: el Estado chileno, el Ministerio de Relaciones Exteriores de Noruega, la Agencia Española de Cooperación Internacional al Desarrollo, UNIFEM y las fundaciones Ford, Open Society Institute, Sigrid Rausing Trust, John Merck y Overbrook.

Nuestros especiales agradecimientos a Claudia Sarmiento, quien forma parte del equipo de investigadores del Centro, por su infatigable dedicación a la siempre esmerada edición de este Anuario.

\section{Cecilia Medina Quiroga}

Directora

Centro de Derechos Humanos 